\title{
Characterizing E-learning Practices in Companies
}

\author{
an exploratory research in Australia
}

\author{
Bianca Smith Pilla ${ }^{1}$, Marina Keiko Nakayama ${ }^{1}$ and Paul Nicholson ${ }^{2}$ \\ 1 Universidade Federal do Rio Grande do Sul, Programa de Pós-Graduação \\ em Administração, Escola de Administração, Brazil \\ 2 Deakin University, Faculty of Education, Australia
}

\begin{abstract}
It becomes perceptible that each day more companies make use of e-learning for the capacity of its workers. During a congress in the e-learning area it has been noticed the increase in corporative e-learning cases. These cases show that there does not exist a single form of e-learning within the companies. Each program makes use of adequate practices for organizational characteristics, which may vary according to each company's knowledge, the technology, the available resources, and the vision administrators have concerning e-learning. Thus, this paper aims to characterize some of these different e-learning practices. Exploratory research was carried out where elearning specialists were interviewed in nine different companies and a university in Australia. The results revealed successful accounts as well as challenges that must overcome. These results will form the basis for later research where an evaluation system that can be adaptable to each corporate elearning practice will be developed.
\end{abstract}

\section{Introduction}

We live in the transition from current society to a knowledge society. In the latter the changes are extremely fast, providing a need for people and organizations to be constantly updated. In this context, organizations would rather choose workers that are able to go along with the changes and remain updated searching for innovation. In private companies, to maintain a highly capable staff may be a strategy to standout before competition. Public organizations also have this constant need of capability to better serve the citizen who is ever more demanding. People are trying to learn more in an attempt to go along with the transformations and to hold on to their jobs.

One alternative used in this process is Distance Learning (DL), a teachinglearning modality where teachers and students interact in different time and/or space. The idea of distance learning is not new. Seen some time ago as second-hand learning, today with the advance in information and communication technology, it is

Please use the following format when citing this chapter:

Pilla, B.S., Nakayama, M.K, Nicholson, P., 2006, in International Federation for Information Processing, Volume 210, Education for the $21^{\text {st }}$ Century-Impact of ICT and Digital Resources, eds. D. Kumar, and Turner J., (Boston: Springer), pp. $145-154$ 
here to stay. Distance learning has been gaining ground in company and academic areas with a tendency for personal capacity.

In the corporation context, DL is normally in the form of e-learning and may be a strategic solution in improving organizational competency and democratizing knowledge. This is why there are so many companies using e-learning to improve the capabilities of their employees.

However, it is still considered new in the enterprise ambit. The non-existence of a form of e-learning is perceptible: each program uses different practices appropriate for organizational characteristics that vary according to the learning process of each company, the technology, available resources, and the vision administrators have concerning e-learning.

In order to know the different practices in e-learning, exploratory research took place in which several e-learning specialists were interviewed in different sectors of nine companies in Australia. The research query was: "What are the characteristics in e-learning practices in companies in Australia?"

Australia was chosen because it is a country where e-learning is relatively consolidated. E-learning there is a reality in teaching institutions as well as in companies. The financial support for the research was given by a Brazilian governmental agency - Conselho Nacional de Desenvolvimento Científico e Tecnológico $(\mathrm{CNPq})$, to which we are grateful.

The results described in this paper reveal successful accounts and future challenges to overcome. These results will subsidize later research where an evaluation system, adaptable to each corporative e-learning practice, will be developed.

The next section presents the literature review and the following sections introduce methodology procedures, results, conclusions and references.

\section{Literature Review}

The study has its grounds on three subjects: e-learning, learning, and evaluation. Next, the main concepts are brought up.

\subsection{E-learning}

The e-learning concept that is being adopted in this research is the same $\mathrm{Na}$ Ubon and Kimble [1] use for online distance education:

"Formally and systematically organized teaching and learning activities in which the instructor and the learner (or learners) are geographically separated, using information and communication technologies to facilitate their interaction and collaboration." [1, p. 468]

E-learning is capable of satisfying the needs that exist in lifelong education, integrated in working areas and to individual needs and expectations. Lifelong education is important when it concerns the need to reformulate the initial formation of people, develop integrated actions on continuous formation, and to transform working areas into learning organizations [2]. 
There are several benefits in e-learning for the organizations. Rosenberg [3] brings us: reduction of costs in training, an improvement in the company's lead time, consistent and personalized messages, content reliance, constant learning, better use of time, accessibility, community build-up, the exploitation of corporation investment on the Web, and the aggregation of the value of services to customers. Considering these benefits, we see that the e-learning market has been increasing significantly in the past years.

\subsection{Learning}

The aim of any e-learning program is to learn. It is regarded that learning is a change of conduct [4]. The people in the corporate ambit build and change an organization through learning.

Argyris and Schön [5] point out that the organizations learn something when their individual members or a fraction of them learn. Organizational learning, therefore, has to do with a process of collective learning. These concepts of organizations that learn are framed by a constructivist approach defended by theorists who encourage e-learning. In constructivism:

"...there is the notion that nothing, strictly, is done or finished, and that, specifically, knowledge is not given at any moment as something complete." [6]

According to Becker [6], one builds up his knowledge on interaction physically and socially, that is, this build-up depends on one's conditions and the environment. Knowledge is seen as a construction, corroborating Piaget's theory. Hence, elearning, by using constructivism, is concerned with collective learning.

Another approach that has been adopted in virtual training surroundings is Action Learning. According to Nicholson [7], this is a participative learning model where learning comes from experience. In this model the participants share their understandings and develop new ideas for their job knowledge through discussion actions, query, guidance, and personal reflection.

Ingram, Sandelands and Teare [8] also defend this approach. They believe that there is no competition in this sort of learning and only room for collaboration. It is not dictatorial, but a facilitator. That is, all may commit mistakes, but are directed to the correct route.

These approaches are compatible with organizations that operate in complex environments where requested knowledge is quite diffused. Nevertheless, due to its complexity the authors emphasize the importance of evaluating the efficiency of the learning process $[5,4]$. Ingram, Sandelands and Teare [8] defend the evaluation of this type of program and point out the importance to evaluate the investment. The issue on evaluation appears to show more when it comes to e-learning programs.

\subsection{Evaluation}

Evaluation is the base of a process of a measurement of results, a crucial element in Human Resource (HR) and in company training. The evaluation model of Kirkpatrick [9] is a reference in corporative distance learning. According to him, the reason for the evaluation of a training program is to determine its effect. He then 
proposes four levels that represent a sequence to evaluate training programs. Each level is important and has impact on the next. The four Kirkpatrick levels are:

1. Reaction - did the trained like the training?

2. Leaning - did they learn?

3. Behavior at work - are they applying/using?

4. Impact on the organization - did it make a difference?

Nisenbaum [10] asserts that levels 1 and 2 are the most used in companies, while 3 and 4 are still less applied. Phillips and Stone [11] include a fifth level, the evaluation of the return on investment (ROI) in training. They present a review on the Kirkpatrick levels and add the fifth level as shown below:

Table 1. Levels of Objectives. Source: Phillips and Stone [11, p. 38].

\begin{tabular}{|c|c|}
\hline Level of Objectives & Focus of Objectives \\
\hline $\begin{array}{l}\text { Level } 1 \\
\text { Reaction/ Satisfaction }\end{array}$ & $\begin{array}{l}\text { Defines a specific level of satisfaction and reaction to the } \\
\text { training as it is delivered to participants. }\end{array}$ \\
\hline $\begin{array}{l}\text { Level } 2 \\
\text { Learning }\end{array}$ & $\begin{array}{l}\text { Defines specific knowledge and skill(s) to be } \\
\text { developed/acquired by training participants. }\end{array}$ \\
\hline $\begin{array}{l}\text { Learning } \\
\text { Level } 3\end{array}$ & $\begin{array}{l}\text { developed/acquired by training participants. } \\
\text { Defines behavior that must change as the knowledge and }\end{array}$ \\
\hline $\begin{array}{l}\text { Application/ } \\
\text { Implementation }\end{array}$ & $\begin{array}{l}\text { skills are applied in the work setting following the } \\
\text { delivery of the training. }\end{array}$ \\
\hline $\begin{array}{l}\text { Level } 4 \\
\text { Business Impact }\end{array}$ & $\begin{array}{l}\text { Defines the specific business measures that will change } \\
\text { or improve as a result of the application of the training. }\end{array}$ \\
\hline $\begin{array}{l}\text { Level } 5 \\
\text { ROI }\end{array}$ & $\begin{array}{l}\text { Defines the specific return on investment from the } \\
\text { implementation of the training, comparing costs with } \\
\text { benefits. }\end{array}$ \\
\hline
\end{tabular}

This evaluation model is the most disseminated in companies that evaluate their training programs, be it present or by distance. However, it is perceived that many companies cannot make total use of this model without difficulties in the process. According to Levy [12], these conventional measurement metrics must evolve in order to supply significant information.

\section{Methodological Procedures}

\subsection{Research Design}

The research done in Australia was exploratory and qualitative.

\subsection{Participants}

For the pre-test, a professor responsible for e-learning in an Australian university was invited. The objective was to test the instruments before conducting the research in the companies. It has also served to test the interviewing procedures, 
such as to schedule the interview, to interview the person, to record the conversation, to transcribe the tape and to analyze the data. We have concluded that instruments and time for interviewing were appropriate for the research.

The research participants were all e-learning specialists in Australian companies. People who manage e-learning practices in business were observed. They were chosen by accessibility and convenience.

\subsection{Analysis Technique}

The technique to analyze the data was the content analysis based on Bardin [13]. Demographic data from the interviewed and the companies were used to characterize the sample.

The content analysis began with pre-determined categories referring to e-learning practices as follows: infrastructure and human resources (HR); design; participants; evaluation; benefits and limitations; future plans and desires. These categories were not regrouped because they can already provide a good level of analysis. The results, according to the categories, are presented in the next section.

\subsection{The Interviewed and the Companies}

After the pre-test interview, interviews with the companies' specialists took place. Nine people in total were interviewed, five women and four men. Five ranged from the ages of 30 to 39 predominantly. Three were in their forties, and only one over fifty. Six are post-graduate and most have a background in business (four) or education (three), while two are specialized in business and in other areas. All research participants are managers or leaders of a team, except one.

Table 2. Companies. Source: elaborated by the authors.

\begin{tabular}{cccc}
\hline Companies & Area & $\begin{array}{c}\text { Number of } \\
\text { employees }\end{array}$ & $\begin{array}{c}\text { Number of e-learning } \\
\text { completions in 2004 }\end{array}$ \\
\hline A & Bank & 28,000 & 24,500 \\
B & E-learning provider & 6 & Approx. 800 \\
C & Retailer & 188,000 & Over 47,000 \\
D & Training provider & 80 & Over 100,000 \\
E & Bank & 8,500 & 9,000 \\
F & Bank & 27,000 & Not informed \\
G & Bank & 45,000 & 25,000 \\
H & Entertainment company & 6,000 & Approx. 3,000 \\
I & Food industry & 3,300 & 200 \\
\hline
\end{tabular}




\section{Results: E-learning Practices of Australian Companies}

\subsection{Infrastructure and HR}

The companies in our sample have used e-learning between 3 months and 5 years. It shows that e-learning is still new in the companies. The person who provides directions for the e-learning is usually Learning or Training Manager.

The number of courses offered by the companies varies drastically. We asked the number of courses they offered the past year because they have e-learning courses in different phases and we needed a standard of comparison. It ranges from two or three courses to 650 . What we have noted is that the companies that have many courses adopt short modules and each module or small course counts as a course. The opposite also occurs. In company $\mathrm{H}$, for example, there are just three courses and one of them is the Microsoft Package, which includes some other courses (Word, Excel, etc).

The staff number for e-learning also varies. It is from three part-time people to fifty part-time people. Part-time means there are companies that do not have a team just for e-learning. They also have the role to provide face-to-face training. The specialization of the staff lies in Education/Training, Management, IT and Administrative. The highest rates of specialization are in the educational area (some companies have more than $80 \%$ of the e-learning staff with this specialization).

The budget for e-learning also varies. It goes from less than AUSD 100,000 to probably around AUSD five million. One company $(\mathrm{G})$ has a budget higher than AUSD ten million, but this value includes face-to-face training. In a certain way, the e-learning budgets are according to the size of the companies and the number of courses they offer.

Summarizing this category, we can say that e-learning has different infrastructures in the companies. The e-learning practices differ in terms of size, budget, staff and management style. The only common aspect is that e-learning is recent and it is being developed gradually. There are many things to develop and to improve and each step is a challenge. Hence, there is a growing market for elearning developers.

\subsection{Design}

The design of e-learning is one of the categories that have surprised us. Starting with the teacher aspect, six of the nine companies do not have teachers in their e-learning courses. We think they probably have, but maybe they do not recognize these people as teachers. They might be internal or external professionals who create or develop the content of the course, like content specialists. The other three companies that have teachers listed as a teacher's role: learning design, content development and learning support.

The question about tutoring was also surprising. We could not find a standard. One company has a teacher and does not have tutors. Two companies have teachers and tutors. Five companies have neither teachers nor tutors. And one company does not have teachers, but has tutors. In the companies where there are tutors, they have 
the role to facilitate and support the learners. The most used technology for tutoring is the telephone. In company $\mathrm{D}$, they do not have tutors, but there is a Help Desk service. Also some companies use e-mail and face-to-face.

In synthesis, the e-learning design seems to be a bit confused in the companies. The technology might be covering the teacher's role. In the companies where there are tutors, we believe this function could be highlighted. Some companies have brought up a help desk, a call center or an interesting e-coach model. Thus, we have not found standards in this category. Also the pedagogy is not clear for the companies. This is an area that could receive more attention. The companies could obtain a design with more collaborative e-learning practices where people can interact through technologies, share and build knowledge and experiences, have new ideas, work in teams or communities and solve problems.

\subsection{Participants/students}

The researched companies use e-learning to train their employees as do the elearning providers (companies $\mathrm{B}$ and $\mathrm{D}$ ). Casual workers also participate in elearning courses in six companies. In some companies, e-learning goes outside to train suppliers (D and $H$ ), partners (A), and even the community and relatives (A). This means that e-learning is not only a program from the HR or training department, but also a business program.

\subsection{Evaluation}

We have found many different aspects about e-learning evaluation. We start by describing how the companies are using the evaluation levels of Kirkpatrick [9] and Phillips and Stone [11]: reaction, learning, behavioral changes, results and ROI.

As it was expected, almost all companies evaluate level 1 - reaction or students satisfaction. Most do a survey after each e-learning course, using a questionnaire. Only in company $\mathrm{A}$ is it carried out when the courses are being developed. Two companies have said that they do this online. In company $\mathrm{C}$, the survey is used also to get information about the learner and demographics. It provides both qualitative and graphical information, like recommendation and satisfaction rates.

The next level is the learning evaluation. Seven companies do it and two do not. What is curious is that company $\mathrm{H}$ evaluates level 2 and does not evaluate level 1 . It is one indication that the levels can be independent and, if they are independent, they are not real levels, but only different aspects that are evaluated. The learning evaluation is usually done through tests and assessments. Each e-learning course can preview this kind of evaluation when it is designed. Company B conducts preassessments to check the knowledge of the group and to customize the training. It tries to design courses where people perform activities that relate directly to them and to the work they do in the workplace.

Concerning behavioral changes (level 3), we have noted that only two companies ( $E$ and $G$ ) have reported that they evaluate this level. Only company $E$ has explained how they do this. It is called application level and it is a responsibility of each manager to do the evaluation because it occurs in the workplace. For this mostly they are using case studies. 
In our sample, four companies also evaluate the results of the e-learning (level 4). Some of them $(\mathrm{C}$ and $\mathrm{H})$ have this kind of evaluation and do not have the evaluation of the previous level. To evaluate results, company $\mathrm{C}$ interviews the managers in order to receive feedback about the application in the workplace. It focuses on specific business outcomes. For company E, this level is harder to evaluate and what they do is show in the report the demonstration of some cases that have clear impacts. In company $\mathrm{H}$, the results of e-learning are the outcomes of the compliance audit.

The return on investment, as expected, is the least-evaluated level. Just two companies - $\mathrm{C}$ and $\mathrm{E}-$ do that. We believe one reason for this fact is that most of elearning courses are about compliance, and this is an obligation. Companies have to do that to maintain their operations and the best way to train in compliance is through e-learning.

Many companies make a comparison with face to face training, looking at the cost, as company $\mathrm{F}$ has reported. We think this comparison is really important, not only for cost comparison but also for time and accessibility comparison.

\subsection{Benefits and Limitations}

We have asked those who were interviewed what are the main benefits of e-learning for their companies. There is no doubt that finance is the most important aspect. But also the equity in accessing learning and the advantage of having quicker learning or time and travel savings (comparing to face to face) are often-mentioned benefits by the companies. In company $\mathrm{H}$, for example, with e-learning they have reduced the time of a certain course from six weeks to approximately two weeks. Company D has a printed brochure where it clearly tells the benefits companies can get by using its e-learning product: accessibility, automatic record keeping, easily updated, engaging and intuitive.

On the other hand, those who were interviewed have issued a list of limitations that companies ascribe to e-learning. Technology stands out among the rest. In company $\mathrm{C}$, for example, the challenge is to integrate the Learning Management System (LMS) with the new HR system. But there also are concerns about how to engage the e-learner and the manager, about how to evaluate, and also about the changes that are caused by e-learning in the management process. Another challenge for e-learning is the time people have to complete the courses. This aspect has appeared also in the pre-test interview. It is not only a problem of employees in companies. It is a society problem. A difficulty encountered by company $\mathrm{E}$ is the short time the staff has to evaluate e-learning.

\subsection{Future Plans and Desires}

Our last question was about the plans companies have for e-learning for the next five years. We had also asked about things they would like to improve. Analyzing these answers, we note they are dispersed, but there are many ideas to be concretized and work to be done. The aspects given by more then one person were in the following order: a more blended learning, a more interactive e-learning, and a more planned and/or strategic e-learning. They are tendencies for e-learning. 


\section{Conclusions}

After this research, we finally arrived at some conclusions on the e-learning practices of Australian companies. We can encounter many positive aspects while others can be improved. The companies provided us with some ideas for the future development of an e-learning evaluation system. In this section we present the main findings and our insights.

We can see that e-learning is still new for companies in Australia, but there are many available courses where thousands of people have already taken advantage. It is an irreversible tendency in companies and in educational institutions that is growing admirably. We have found some companies that use e-learning not only for employee training, but also outside the company. In our research, we can point-out some differences between the e-learning practices, such as the infrastructure companies have. Even with these little differences, companies have one common focus for e-learning: compliance training. It is a reality that e-learning is helping the Australian companies to be compliant and this is very important for them.

On the other hand, we think that e-learning has a huge potential and could be far more strategic. All companies have their organizational strategies very clear, but when we talk about e-learning, it appears to be lacking in a strategic approach.

E-learning is much more a "mass training" than something more elaborated. The excess of concern about cost reduction influences a standardized design, with poor interactions between people and little innovation. But we think it will change in the next few years because we could see the desire of those interviewed to improve their practices.

When it comes to e-learning evaluation, at this moment we propose some directions based on the practices we have investigated. Our study reveals that the evaluation training model of Kirkpatrick is not entirely used by Australian companies. We think the idea of levels is not adequate for the companies today, but some aspects of his model are still useful.

Most companies use the smiley sheets to evaluate their students' satisfaction towards the program. We think they should continue to use them if they provide good information to improve their e-learning practices. We suggest they maintain this just for the new courses and do it online, because when the course is wellestablished it is not necessary to do any further survey. It results in too much work. Companies could open another tool of communication to collect free feedback from the students. Both the satisfaction survey and students' feedback may be done online. It saves time and money in this process.

Regarding learning evaluation, we like what company B does: it tests the student's knowledge before designing the course. We suggest this for the other companies when they have a new course and people have previous knowledge. It can also be done online. Learning evaluation is important and we believe that assessments are a quick way to do it. Yet, if possible, more elaborated evaluations should be done, like case studies and simulations. Most of them can be done online depending on what kind of course is being offered.

We did not find many evidence of behavioral change evaluation. We think the most important aspect to be evaluated is the result of the training and it can be done 
simultaneously with students' satisfaction and learning evaluations. Our research shows that even if some companies do not have a formal result evaluation, they have an informal way to do it. They know the benefits of their e-learning and limitations. The difference is that if they have an informal evaluation they do not have a way to assert that these results really come from e-learning.

We propose that the result evaluation may be planned at the moment the course is developed. It will vary according to each course and it is impossible to establish a standard model. But there is one important matter that should be highlighted: involving the line managers in this process is a fundamental task. The research also shows that to calculate ROI is not always useful. Sometimes, in compliance training for example, the best financial evaluation is to compare e-learning with face-to-face training, as compliance does not provide direct profits. It is an obligation.

\section{References}

1. Na Ubon and C. Kimble. Knowledge management in online distance education. In: Proceedings of the $3^{\text {rd }}$ International Conference Networked learning 2002, University of Sheffield, UK, March 2002, p. 465-473.

2. M. L. Belloni. Educação a Distância. (2. ed, Autores Associados, Campinas, 2001).

3. M. J. Rosenberg. E-learning: estratégias para a transmissão do conhecimento na era digital (Pearson Education, São Paulo, 2002).

4. J. Swieringa and A. Wierdsma. La organización que aprende (Addison-Wesley, Wilmington, 1995).

5. Argyris and D. Schön. Organizational learning II: theory, method and practice (AddisonWesley, Wilmington, 1996).

6. F. Becker. Educação e construção do conhecimento (Artmed Editora, Porto Alegre, 2001).

7. P. Nicholson. E-training or e-learning? Towards a synthesis for the knowledge-era workplace, in: P. Nicholson et al. (eds). Etraining solutions for professional organizations: proceedings of Etrain 2003 (Kluwer, New York, 2003).

8. H. Ingram, E. Sandelands and R. Teare. Building high performance learning: a focus on career results and the business bottom line. The learning organization; v. 8; n. 5, p. 211219 (2001).

9. L. Kirkpatrick. Evaluating training programs: the four levels. ( $2^{\text {nd }}$ ed., Berret-Koehler Publishers Inc., San Francisco, 1998).

10. H. Nisenbaum. Treinar é preciso. Medir também é preciso. In: E-learning Brasil News (December 19, 2003); http://www.elearningbrasil.com.br.

11. J. J. Phillips and R. D. Stone. How to measure training results (McGraw-Hill, New York, 2002).

12. J. D. Levy. Medindo e maximizando resultados através do e-learning. In: E-learning Brasil News (December 11, 2003); www.elearningbrasil.com.br

13. L. Bardin. Análise de conteúdo (Edições 70, Lisboa, 1977). 